\title{
Adhesion-strength and tribotechnical properties of machine-building composite polymer coatings
}

\author{
Soyibjon Negmatov, $T$ Ulmasov, $M$ Karshiyev, $Z$ Makhammadjonov", $O$ Abdulayev, and $M$ \\ Matsharipova \\ Tashkent State Technical University named after I.Karimov, Tashkent, Uzbekistan
}

\begin{abstract}
The article presents the results of studies of adhesive, strength and tribotechnical properties of composite polycaproamide polymer materials and coatings based on them for mechanical engineering purposes. It has been established that the relative change in the adhesion strength depends on the degree of filling in air and in argon has an extreme character passing through a maximum for coatings based on PCA with aluminum oxide, and for coatings made of PCA with copper oxide, it has a complex character. The formation of adhesive, strength, and tribotechnical properties of filled polycaproamide coatings was also studied. At the same time, it was found that by adjusting the temperature-time technological modes, it is possible to increase the adhesive, strength, and tribotechnical characteristics of composite polycaproamide coatings for machine-building purposes.
\end{abstract}

\section{Introduction}

Today, on a global scale, much attention is paid to improving the efficiency, performance, and durability of machines and mechanisms. Of particular importance is an increase in the adhesive and strength properties of coatings made of composite polymer materials and a decrease in their coefficient of friction and wear, which ensure an increase in the service life of the working bodies of machines and mechanisms [1-14]. Composite polymer materials and coatings made of them can protect the working bodies of machines and mechanisms from friction and vibration [7, 9]. It has been established that in mechanical engineering, friction tests are the most difficult type of assessing the properties of materials $[1,2,9,15],[18-20]$; in addition, the reason for the increase in polymer adhesion when filled with solid dispersed fillers has not yet been sufficiently clarified. Therefore, there is no method for choosing fillers to strengthen it. Therefore, a study to identify the relationship between the friction composition with other physical and mechanical properties of the adhesive and the substrate and coatings is an urgent task. In this regard, this work aims to study the mechanism of contact interaction of materials, adhesive, strength, and tribotechnical properties of composite polymer materials and coatings based on them for

\footnotetext{
*Corresponding author: m.zohidullo@mail.ru
} 
machine-building purposes, operating under conditions of frictional interaction with contour bodies.

\section{Materials and Methods}

Polycaproamide of grade B, organomineral fillers with relatively high physical and mechanical properties $[1,2,8,10,11]$, was chosen as the research object. In the experiments, we used powdered polycaproamide grade B with a dispersion of up to 250 microns. The adhesion of the coating to the steel was determined by the method of normal pull-off at a constant speed $(0.5 \mathrm{~N} / \mathrm{sec})$ and characterized by the value of the breaking stress. Samples for assessing cohesive properties were prepared under the same conditions as samples for assessing adhesion according to the method described in $[1,2,8,10]$, $[15-$ 20]. For comparative tests of the frictional properties of coatings in MS-20 oil, the technique described in [2] was used. Coatings and samples for evaluating adhesion were obtained according to the method [4]. The formation medium was air and argon [13, 14].

\section{Results and Discussion}

We have investigated the adhesive, cohesive and frictional properties of polycaproamide coatings filled with organomineral ingredients to reveal the relationship between these basic properties of polymer coatings. With the introduction of a filler with aluminum oxide into polycaproamide, the nature of the dependence of adhesion on the increase in the content of the filler under the action of the formation medium, in the case of filling the polymer with aluminum oxide, they have an extreme character of passage through the maximum, and in the case of filling with copper oxide, adhesion has a complex character Figure 1, (a). At the same time, the maximum attainable value of adhesion during the formation of bonding in the air is higher than in argon. A similar picture is observed when filling the polymer with lead oxide, copper oxide, and some other inorganic fillers. When PCA is filled with copper oxide in various media, Figure 1, (b), the nature of adhesion depends on the percentage of filling changes when air is replaced with argon. Changes of similar nature are also noted with the introduction of copper oxide and the antioxidant Neozon D. The adhesion of polycaproamide is influenced by temperature-time factors and their mechanism of action. However, a change in adhesion during filling can also be due to the absorption of low molecular weight compounds by the filler, which forms weak boundary layers, in particular low molecular weight contaminants contained in the polymer or on the metal surface, products of oxidative destruction and contact reactions, as well as modifiers (antioxidants, plasticizers, etc.). [five]. For example, as shown by the results of studies, inorganic fillers can effectively adsorb low molecular weight HDPE thermal oxidation products such as carboxylic acids, which leads to both an increase and a decrease in HDPE adhesion to a solid [6]. Consequently, the change in the adhesion of the filled PCA, Figure 1, (b) during the formation of bonding in the air can be explained by the influence of oxidative and sorption processes. Ultimately, the absolute value of adhesion and its nature depend on which process prevails - the slowing down of oxidative processes due to the adsorption of low-molecular substances by the filler or the initiation of a thermo-oxidative polymer melt due to the catalytic activity of the substrate. Apparently, this is why the lower value of the maximum achievable adhesion when filled with aluminum oxide for coatings formed in an argon atmosphere, Figure 1 (a, curve 2). 

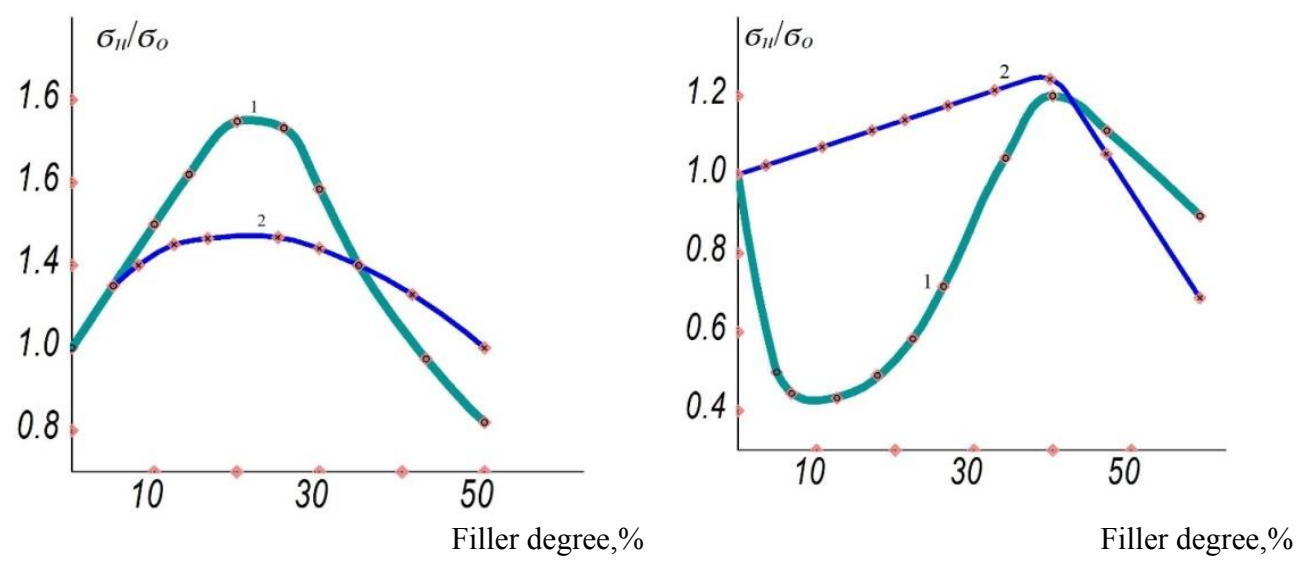

Fig.1. Relative change in the strength of the adhesive joint depending on the degree of filling in air (1) and in argon (2) (a - PCA + alumina, b - PCA + copper oxide).

In this case, redox processes and processes associated with structuring and destruction occur in the bulk of the polymer. The strength of the adhesive bond is determined by the cohesive strength of the film. Suppose the filler is inert with respect to the thermal oxidation of the polymer melt and is unable to adsorb low molecular weight products of thermal oxidation. In that case, a decrease in adhesion can be expected since low molecular weight products of thermal oxidation penetrate the adhesive contact boundary. The nonmonotonic change in the adhesion of PCD upon filling with copper oxide, apparently, this explains Figure 1, (b, curve 1). Consequently, inorganic fillers actively affect the strength of the PCA - steel adhesive joint. They can both increase and decrease the adhesion of PCD to a solid. It depends on the nature of the substrate, the sorption capacity, the activity of the filler, and the temperature-time factors of the formation of the compound. Further, complex studies of adhesive, strength, and tribotechnical properties of filled polycaproamide polymer coatings were carried out. Figure 2 that the adhesion of polyamide coatings obtained in the air changes symbatically with an increase in the preheating temperature of the metal (PTM), and the friction coefficient is antiradical to the microhardness of the coatings (curves 1-3). With an increase in the duration of the formation temperature, the adhesion of coatings obtained at temperatures below $600^{\circ} \mathrm{K}$ increases reaches a maximum, and then falls. With an increase in tempera, the time to reach the limiting adhesion decreases, and its maximum values are the same, Figure 2 (curve 5). For the PTM interval of $600^{\circ} \mathrm{K}$ and higher, an increase in temperature and duration of its action leads to a decrease in adhesion. Comparative analysis from experimental data shows that an increase in the temperature of formation in terms of the nature of the effect on adhesion is equivalent to an increase in the duration of its action. The effect of the formation temperature on the viscosity of a $0.5 \%$ solution of the coating material in tricresol and the amount of lowmolecular substances extracted by boiling in benzene was also studied. Comparison of these data with the data obtained by us showed that the nature of the dependence of the microhardness on PTM coincides with the nature of the dependence of the viscosity of the coating material and is opposite to the nature of the dependence of the amount of substances extracted from the coatings on PTM. This indicates that with an increase in PTM, the change in microhardness, adhesion, and the friction coefficient is due to the chemical structuring (crosslinking) of macromolecules. The introduction of dispersed aluminum oxide leads to an increase in adhesion, polycaproamide coatings Figure 3, (curve 1). With an increase 


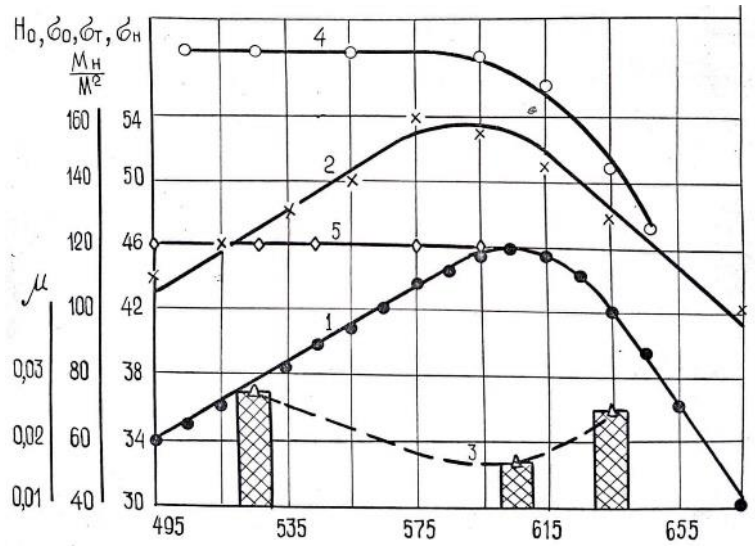

Fig. 2 Dependence of the physical and mechanical properties of polycaproamide coatings on PTM: 1 is adhesion (PAS), 2 is microhardness, 3 is coefficient of friction, 4 and 5 are limiting values of adhesion, respectively, with the introduction of a filler and with a significant effect of PTM.

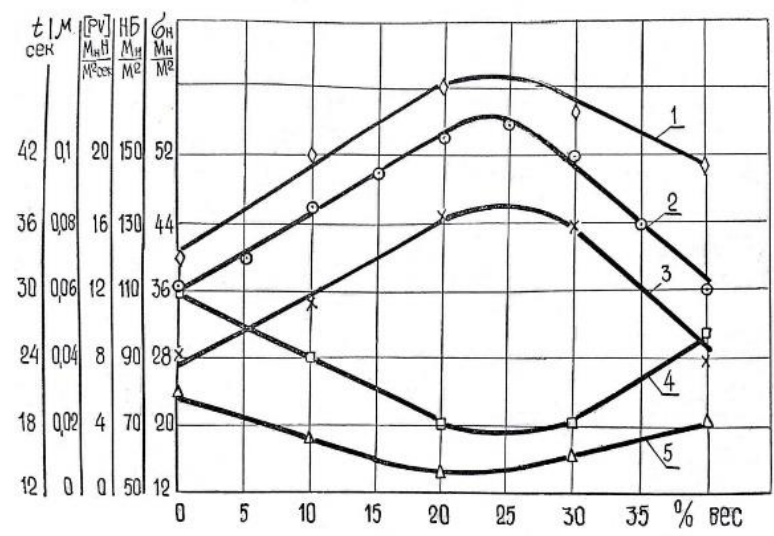

Fig. 3 Dependence of the physical and mechanical properties of polycaproamide coatings on the content (weight,\%) of the filler (PTM $525^{\circ} \mathrm{K}$ ): 1 is carrying capacity; 2 is adhesion; 3 is Brinell hardness; 4 is running-in time of coatings; 5 is coefficient of friction.

(relative increase in adhesion) decrease and the maximum adhesion values attainable while filling in the PTM range up to $600^{\circ} \mathrm{K}$ are approximately the same in Figure 2 (curve 4). With an increase in PTM, the critical filler concentration values corresponding to the adhesion maxima and the filling efficiency (relative increase in adhesion) decrease, and the maximum adhesion values attainable while filling in the PTM range up to $600^{\circ} \mathrm{K}$ are approximately the same in Figure 2, (curve 4).

\section{Conclusion}

Thus, by controlling the temperature-time conditions of formation and the introduction of solid dispersed fillers, it is possible to significantly improve the adhesive, strength, and tribotechnical properties of polycaproamide polymer coatings. The relationship between the hardness of coatings, adhesion, and tribotechnical properties of the material makes it possible to predict the frictional properties, as well as the strength of the adhesive bond between the polymer and the substrate (metal), based on the hardness of the films. This greatly simplifies and speeds up the assessment of the properties of modified polymer coatings. 


\section{References}

1. $\quad$ Egorenkov N.I., Nasirov I., Beliy V.A., DAN BSSR , № 12, 1085. (1971)

2. Beliy V.A., Miranovich L.L., Sogolova T.I. Mexanika polimerov. № 2, 195. (1969),

3. Kalnin M.M., Karlivan V.P., Brake R.R., «Visokomolek. soed.», IX, , 10, 2178. (1967)

4. Negmatov S.S., Usloviya ekspluatatsii osnovnix rabochix organov mashin i mexanizmov dlya uborki i pererabotki xlopko-sirsa. Tashkent Izd-vo «Uzbekistan» 60 s. (1980),

5. Bikerman YA.O., «Visokomolek. soed.», A10, , p. 974.( 1968)

6. Egorenkov N.I., Lin D.G., Kuzovkov A.I., «Visokomolek. soed.», (A) XX, , p. 6. (1978)

7. Solomatov V.I., CHerkasov V.D, Fomin N.E., Vibropoglashayuщie kompozitsionnie materiali Izd-vo Mordovskogo un-ta. 95 p.( 2001)

8. Negmatov S.S., Evdokinov YU.M., Sadikov X.U., Adgezionnie i prochnostnie svoystva polimernix materialov i pokritiy na ix osnove. -T.: Izdatelstvo «Fan» UzSSR,. p.168.( 1979)

9. Negmatov S.S., osnovi protsessov kontaktnogo vzaimodeystviya kompozitsionnix polimernix materialov s voloknistimi materialami. Tashkent, Izd-vo., «Fan»,. s. 296. (1984)

10. Berlin A.A., Basen V.E. Osnovi adgezii polimerov. - M.: Ximiya. g. p. 392.( 1974)

11. Voronin I.V., Kondrashov E.K. Dolgovechnost adgezionnix svyazey polimerov pokritiy//Lakokrasochnie materiali i ix primenenie., № 1, p. 25-26.( 1991)

12. Tishin S.A., SHipilevskiy B.A., Tishin V.A., Adegzionnie svoystva epoksidnix polimerov $\mathrm{V}$ prisutstvii visokodispersnix kremnezemov $\mathrm{s}$ modifitsirovannoy poverxnostyu// Lakorasochnie materiali i ix primenenie., № 6.( 1991)

13. Gul V.E., Vaxrushnia L.A., Dvoretsskaya L.M. Visokom, soed., A 18, №1., p. 122.( 1976)

14. Deryagin B.V., Adgezii tverdix tel / B.V. Deryagin, N.A. Krotova, V.P. Smigla// M.: Nauka.. p. 279.( 1973)

15. Negmatov S.S., Texnologiya polucheniya polimernix pokritiy. -T.: Izdatelstvo «Uzbekistan», , p. 232.( 1975)

16. Zimon A.D. Adgeziya pili i poroshkov. M., 1967 i Adgeziya plenok i pokritiy. M. (1977).

17. Beliy V.A.. Egorenkov N.M., Pleskachevskiy YU.M. Adgeziya polimerov k metallam. Minsk, (1971).

18. Lebedev L.M. Mashini i prirodi dlya ispitaniy polimerov. -M., (1967).

19. YAkubovich S.V. Ispitaniya lakokrasochnix materialov i pokritiy, -M.,. p.32.( 1952)

20. Sanjarvskiy A.T. Metodi opredeleniya mexanicheskix i adgezionnix svoystv polimernix pokritiy. - M., (1974) 